\title{
CERVICAL LYMPHANGIOMA IN ADULTS- A RARE ENTITY IN ADULT NECK SWELLINGS
}

\author{
Rajesh Daniel'1, Abhinav Bharadwaj Rajkumar², Prakash Sadasivam³, Maramreddy Lokesh Reddy4, Parivallal Damodaran 5
}

\author{
${ }^{1}$ Assistant Professor, Department of General Surgery, SRM Medical College Hospital and Research Centre, Kattankulathur, \\ Kancheepuram, Tamilnadu, India. \\ 2Postgraduate Student, Department of General Surgery, SRM Medical College Hospital and Research Centre, Kattankulathur, \\ Kancheepuram, Tamilnadu, India. \\ ${ }_{3}^{3}$ Assistant Professor, Department of General Surgery, SRM Medical College Hospital and Research Centre, Kattankulathur, \\ Kancheepuram, Tamilnadu, India. \\ 4Postgraduate Student, Department of General Surgery, SRM Medical College Hospital and Research Centre, Kattankulathur, \\ Kancheepuram, Tamilnadu, India. \\ 5Postgraduate Student, Department of General Surgery, SRM Medical College Hospital and Research Centre, Kattankulathur, \\ Kancheepuram, Tamilnadu, India.
}

HOW TO CITE THIS ARTICLE: Daniel R, Rajkumar AB, Sadasivam P, et al. Cervical lymphangioma in adults- a rare entity in adult neck swellings. J. Evolution Med. Dent. Sci. 2018;7(27):3144-3147, DOI: 10.14260/jemds/2018/707

\section{PRESENTATION OF CASE}

Cystic hygromas/lymphangiomas are extremely rare malformations in adults. They are usually seen in infants and children under 2 years of age. En bloc resection is difficult due to the adhesive characteristics of the tumours. Inadequate surgical intervention often leads to recurrent disease. We report herein the case of a cystic hygroma/lymphangioma that presented as an uncommon mass on the cervical region in an adult.

A 24-year-old male presented with a swelling on the left side of the neck since childhood, noticed to have increased in size for the past six months. It was a solitary $4 \mathrm{cms} \times 3 \mathrm{cms}$, soft, non-tender, ovoid swelling at the left submandibular region with a well-defined margin with smooth surface and the overlying skin was normal. There was no intra-oral extension on bimanual palpation. The routine blood investigations are done and were within normal limits. FNAC and CT neck were done. Patient underwent wide excision, where the intraoperative findings showed a superficial cystic swelling with few loculi over the muscle layer of the mylohyoid and the anterior belly of the digastric with few finger-like extensions between the muscle planes. The swelling was excised in toto. Histopathology reports revealed multilocular cystic swelling lined by fibrous stroma and on microscopy was multiple lymph spaces lined by lymphatic epithelium with a diagnosis of lymphangioma of the neck.

\section{DISCUSSION OF MANAGEMENT}

Cystic hygromas/lymphangiomas are rare congenital malformations of the lymphatic system. Most are seen in the head and neck region (75-80\%) and usually affect children under 2 years of age. ${ }^{1}$ They are quite rare in adults. ${ }^{2}$ The aetiology of hygromas in adults is controversial, but they are thought to be due to proliferation of lymphoid vessels in response to head and neck trauma and/or infection. ${ }^{3}$

'Financial or Other Competing Interest': None.

Submission 23-05-2018, Peer Review 17-06-2018,

Acceptance 22-06-2018, Published 02-07-2018.

Corresponding Author:

Abhinav Bharadwaj Rajkumar,

Room No. 1410, $13^{\text {th }}$ Floor,

SRM PG Medical Gents Hostel,

SRM University, Potheri, Kattankulathur,

Kancheepuram Dist.-603203,

Tamilnadu, India.

E-mail: abhinavbharadwaj39@gmail.com

DOI: $10.14260 /$ jemds $/ 2018 / 707$
Lymphatic tissue can also improperly anastomose with capillaries, veins and arteries. ${ }^{4}$

Microscopically, lymphangioma is characterised by large, dilated lymphatic vessels in a fibrotic or loose stromal background. Focal areas of papillary endothelial proliferation were described aside by the classic histological picture. ${ }^{5}$ The presence of lymphoid aggregates, even lymphoid follicles may be confusing when existing in large amounts and needs to be distinguished from atypical lymphoid proliferations. The main histopathologic differential diagnosis of cystic hygroma is cavernous haemangioma, in which blood filled large cystic spaces were described to be similar to lymphangioma. The lining endothelium of cavernous haemangioma shows positivity with pancytokeratin and factor VIII immunohistochemically. The presence of lymphatic spaces with thin walls containing fibrous tissue, smooth muscle and lymphoid aggregates favours the diagnosis of lymphangioma. ${ }^{6}$ In general, lymphangioma is accepted as a benign tumour with no malignant transformation and curable by excision. ${ }^{7}$

Lymphangiomas can manifest anywhere in the body, but are most commonly seen in cervicofacial regions (Especially in posterior cervical triangle), axilla, mediastinum, groin and oral cavity. ${ }^{8-10}$ More than $95 \%$ of lymphangiomas are situated in the head, neck, axilla and extremities. ${ }^{8-10}$ Although, common in childhood, occurrence in adults is quite uncommon and fewer than 150 reports of adult cervicofacial cystic hygromas have been reported in the literature.11,12 It presents a diagnostic challenge in adults as compared to children and definitive diagnosis is usually based on postoperative histology. ${ }^{11}$ Here, we present the case of a 38-yearold male patient with cystic hygroma in the cervical region.

A 24-year-old male presented with a swelling on the left side of the neck since childhood, noticed to have increased in size for the past six months and there was an increase in size on eating. Patient had no pain over swelling, shortness of breath, dysphagia, dysphonia and no other swelling in body. There was no history of previous surgeries.

\section{CLINICAL DIAGNOSIS}

On clinical examination, a solitary $4 \mathrm{cms} \times 3 \mathrm{cms}$ soft, nontender ovoid swelling was seen at the left submandibular region. The swelling had a well-defined margin with smooth surface and the overlying skin was normal (Figure 1). There was no intra-oral extension on bimanual palpation. 


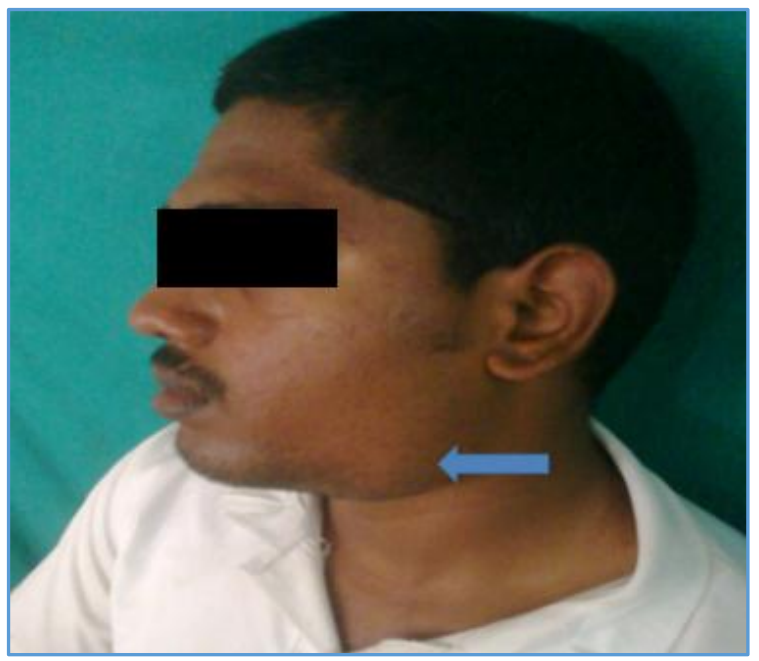

Figure 1. Neck Swelling in the Patient

The routine blood investigations were normal, and the CT-scan revealed a cystic swelling in the left submandibular region with a suggestive diagnosis of a retention cyst in the submandibular gland (Figure 2). FNAC done later only showed serosanguineous fluid.

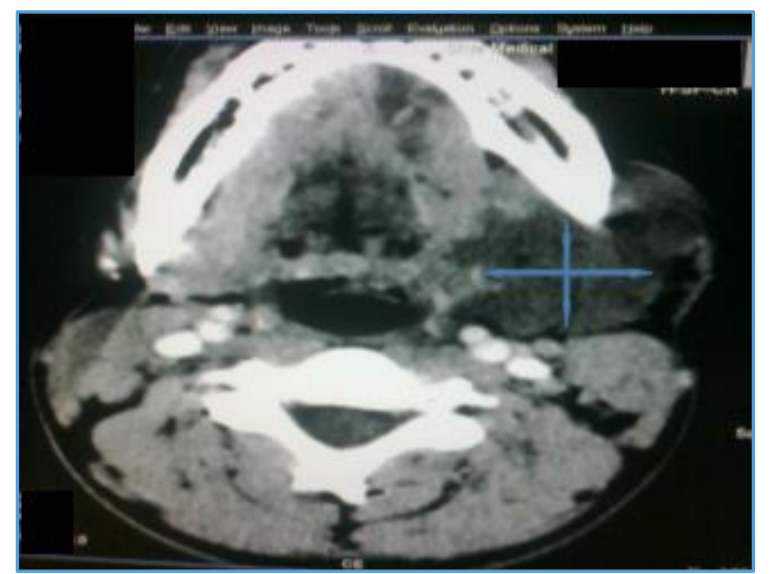

Figure 2. The CT Scan Pictures (Transverse and Sagittal Section) revealing the Tumour with the extent marked by White Double-Sided Arrows

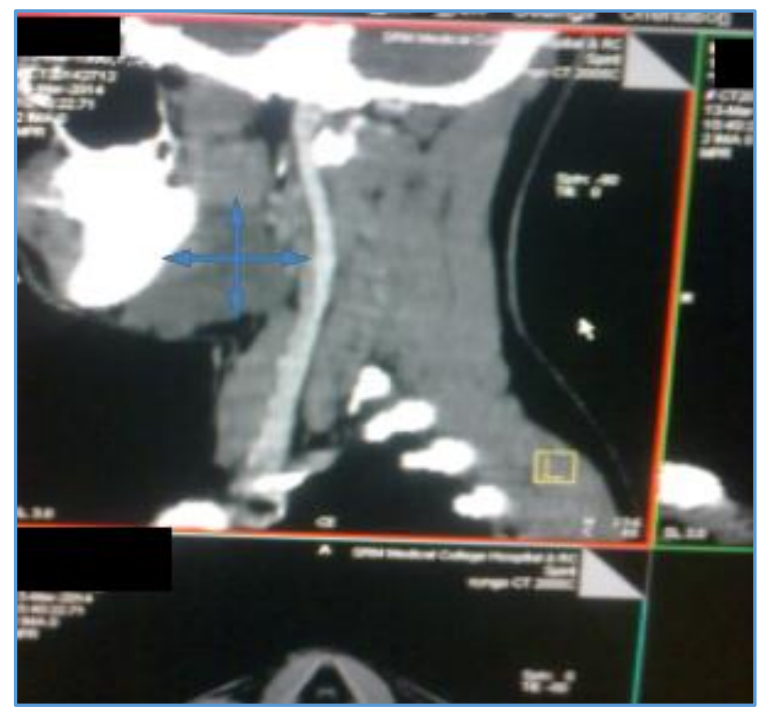

Figure 3. Cystic Lymphangioma

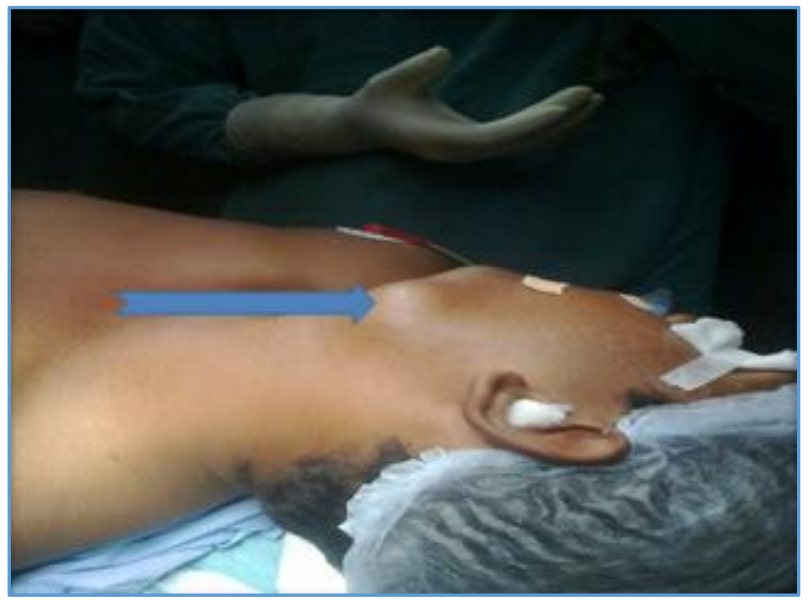

Figure 4

After taking informed written consent, patient had been taken for surgery. A wide excision was made under general anaesthesia. A transverse incision is made over the swelling parallel to the mandible, where the intraoperative findings was that of superficial cystic swelling with few loculi over the muscle layer of the mylohyoid and the anterior belly of the digastric with few finger-like extensions between the muscle planes. Cystic swelling was circumferentially dissected and removed in toto (Figure 4).

Figure 4: Intraoperative Pictures (Short arrow on right pointing to dissected portion of the posterior belly of left digastric muscle. Long arrow on left pointing to the cystic tumour lymphangioma).

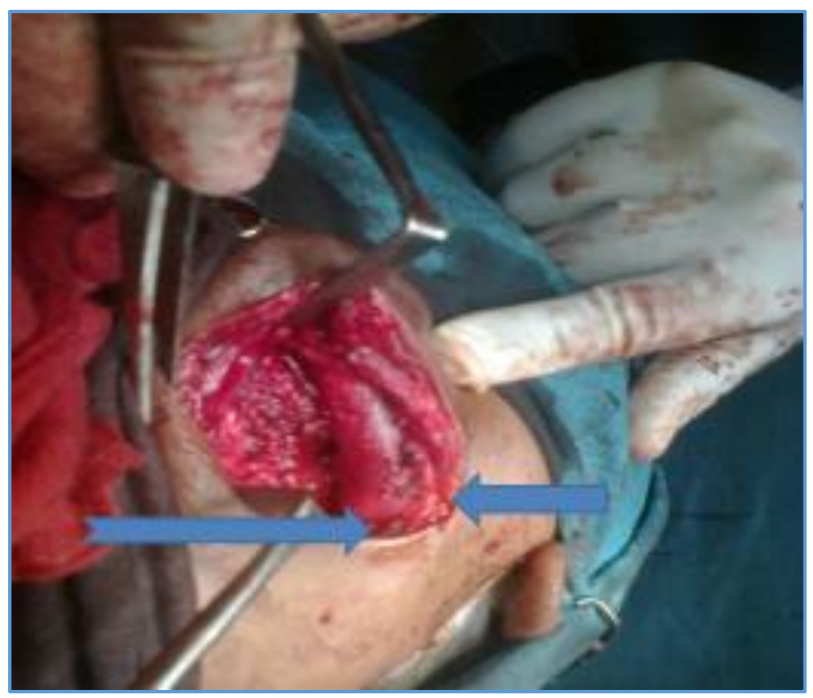

Figure 5

\section{PATHOLOGICAL DISCUSSION}

Care has been taken during dissection to prevent injury to vital structure and the histopathology report gross was a multilocular cystic swelling lined by fibrous stroma and microscopy was multiple lymph spaces lined by lymphatic epithelium with a diagnosis of lymphangioma of the neck.

Figure 5: Histopathological findings of lymphangioma (Long arrow- Cystic areas with lymphoid aggregates; Short arrow- Blood vessels). 


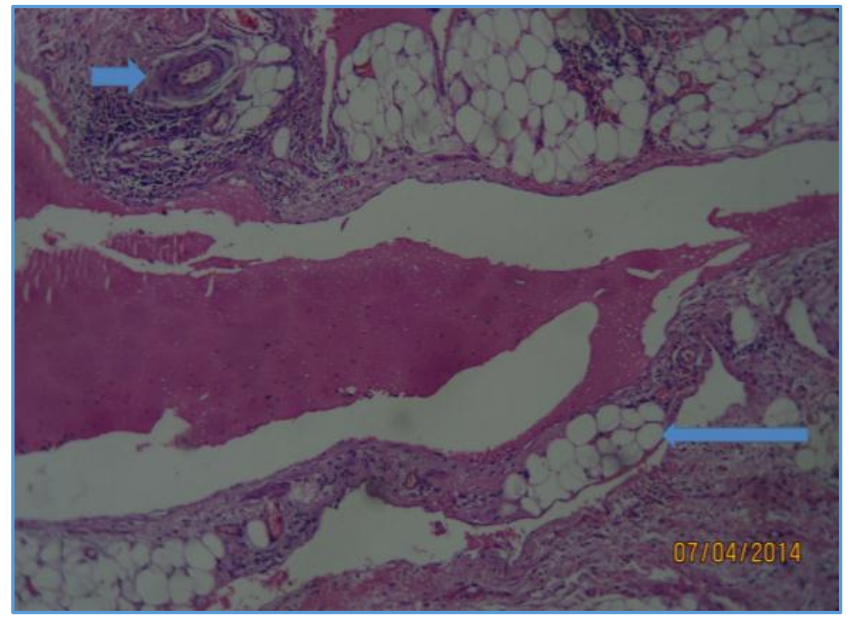

Figure 6

\section{DISCUSSION OF MANAGEMENT}

Cystic hygromas/lymphangiomas are thought to be developmental abnormalities associated with a failure in the embryological connection between lymphoid vessels and venous system and generally not accepted as true tumours. ${ }^{13}$

Three types of cystic hygroma/lymphangioma can be distinguished. The capillary form is usually asymptomatic with small sizes. Although, cavernous and cystic lymphangiomas show the same histological pattern, cystic lesions are usually larger and symptomatic. ${ }^{14}$ Although, more than $90 \%$ of lymphatic malformations are clearly congenital, later presentations were due to trauma, infection, neoplasms or iatrogenic injuries. ${ }^{15}$ The pathophysiology of adult lymphangiomas is not clearly understood, but these lesions may occur secondary to induction of dormant rests of embryonic lymphatic tissue that are stimulated to differentiate and grow.

Robert $\mathrm{P}^{16}$ reported 32 cases of cervical lymphangioma treated at Mayo Clinic between 1950 and 1982. He reported that lesions were seen in all decades of adult life and equally in men and women. Most lesions presented as a rapidly enlarging asymptomatic mass. The anterior triangle of the neck was involved nearly as often as the posterior triangle and right-sided locations predominated (72\%). Histopathologic differentiation of the lesions into simplex, cavernous and cystic lymphangiomas was not helpful in predicting clinical behaviour. Surgical excision is the treatment of choice. The lesions may intimately involve the carotid sheath or adjacent nerves. Recurrence in $21 \%$ of the 28 patients on whom follow-up data were available mostly represented incomplete excision. ${ }^{15}$ Primary treatment for lymphangioma is total surgical excision. ${ }^{17}$ The treatment of choice for cystic hygroma is surgical excision without which there is a danger of infection and fistula formation. Saxena et $\mathrm{al}^{2}$ described that cystic hygroma might infiltrate into adjacent structures, which can lead to recurrence in $10 \%$ $15 \%$ of cases if complete excision is not done.

Other treatment modalities have been reported such as marsupialisation, injection of sclerosing agents and steroids, diathermy and radiotherapy in unresectable or persistent cases.18,19 Injection of sclerosing agents into the lesion such as OK-432 (a lyophilised mixture of group A streptococcus pyogenes of human origin), $50 \%$ dextrose, triamcinolone, bleomycin, fibrin sealant and hydrocolloid impression material has had some success. For recurrent cystic hygroma, intravenous cyclophosphamide and intracystic injection of OK-432 have been advocated. ${ }^{20}$

\section{REFERENCES}

[1] Gow L, Gulati R, Khan A, et al. Adult onset cystic hygroma: a case report and review of management. Grand Rounds 2011;11:5-11.

[2] Saxena P, Chandra D. Cystic Hygroma of neck in an adult female: case report \& literature review. Int J Surg 2010;22(2).

[3] Davies D, Rogers M. Morphology of lymphatic malformations: a pictorial review. Aust J Dermatol 2000;41(1):1-7.

[4] Kasapoğlu F, Yildirim N. Cystic hygroma colli in adults: a report of two cases, one with atypical location. Kulak Burun Boğaz Ihtisas Dergisi 2008;18(5):326-9.

[5] Sherman BE, Kendall K. A unique case of the rapid onset of a large cystic hygroma in the adult. American Journal of Otolaryngology - Head and Neck Medicine and Surgery 2001;22(3):206-10.

[6] Mathew M, Dil SK. Adult lymphangioma-a rare entity: a report of two cases. Turkish Journal of Pathology Derg 2012;28(1):80-2.

[7] Wiegand S, Eivazi B, Barth PJ, et al. Pathogenesis of lymphangiomas. Virchows Archiv 2008;453(1):1-8.

[8] Fonkalsrud EW. Pediatric surgery. Chapter - 133. In: Jay GL, O’Neill JA, Fonkalsrud EW, et al. eds. Lymphatic disorders. Vol. 2. $6^{\text {th }}$ edn. Mosby Inc., 2006: p. 2137-46.

[9] Mirza B, Ijaz L, Saleem M, et al. Cystic hygroma: an overview. J Cutan Aesthet Surg 2010;3(3):139-44.

[10] Liu DK, Ma YC, Guo XN, et al. Surgical treatment of cervical giant cystic lymphangioma in children. Zhonghua Zheng Xing Wai Ke Za Zhi 2011;27(6):4157.

[11] Biasotto M, Clozza E, Tirelli G. Facial cystic lymphangioma in adults. The Journal of Craniofacial Surgery 2012;23(4):e331-e4.

[12] Kuo T, Gomez LG. Papillary endothelial proliferation in cystic lymphangiomas. A lymphatic vessel counterpart of Masson's vegetant intravascular hemangioendothelioma. Archives of Pathology and Laboratory Medicine 1979;103(6):306-8.

[13] Chand EM, McNeely TW, Freant LJ. Pathologic quiz case: male with increasing abdominal girth. Pathologic diagnosis: Multicystic intra-abdominal lymphangioma. Archives of Pathology and Laboratory Medicine 2000;124(11):1723-4.

[14] Gross RE, Hurwitt ES. Cervicomediastinal and mediastinal cystic hygromas. Surgery, Gynecology \& Obstetrics 1948;87(5):599-610.

[15] Kennedy TL, Whitaker M, Pellitteri P, et al. Cystic hygroma/lymphangioma: a rational approach to management. Laryngoscope 2001;111(11 Pt 1):192937.

[16] Schefter RP, Olsen KD, Gaffey TA. Cervical lymphangioma in the adult. Otolaryngology - Head and Neck Surgery 1985;93(1):65-9.

[17] Orvidas LJ, Kasperbauer JL. Pediatric lymphangiomas of the head and neck. Annals of Otology, Rhinology and Laryngology 2000;109(4):411-21. 
[18] Solem BS, Schroder KE, Mair IW. Differential diagnosis of a mass in the upper lateral neck. J Laryngol Otol 1981;95(10):1041-7.

[19] Kaur N, Gupta A, Amratash, et al. Giant cystic hygroma of the neck with spontaneous rupture. J Indian Assoc Paediatr Surg 2007;12(3):154-5.
[20] Seashore JH, Gardiner LJ, Ariyan S. Management of giant cystic hygromas in infants. Am J Surg 1985;149(4):459-65. 